\title{
Microstructure and Microhardness of Fiber Laser Welded Dual-Phase Steels with High-Strength Low-Alloy Steels
}

\section{P. $\breve{S v e c}^{1}$ and A. Schrek ${ }^{2}$}

Faculty of Mechanical Engineering, Slovak University of Technology in Bratislava, Bratislava, Slovakia

\author{
1 pavol.svec@stuba.sk \\ 2 alexander.schrek@stuba.sk
}

The fiber laser welding of dual-phase DP980 steels with high-strength low-alloy LA340 steels was studied with a concentration on microstructure, microhardness, and tensile properties of butt joints. The microstructure in the fusion zone of joints was predominantly built of lower bainite and martensite. Mainly martensite was found in the coarse-grained region of HAZ near DP980 steel, but equiaxed ferrite and tempered martensite were observed in fine-grained region of this HAZ. The microstructure consisted of acicular ferrite, upper bainite and equiaxed ferrite in the high tempered coarse-grained region of HAZ near LA340 steel. The fine-grained equiaxed ferritic microstructure was found in the low tempered region of HAZ near LA340 steel. The microhardness increased in the fusion zone and in both heat-affected zones compared to the base metals, $335 \mathrm{HV}$..1 for DP980 steel and $186 \mathrm{HV}_{0.1}$ for LA340 steel. The microhardness reached values from 380 to $441 \mathrm{HV} V_{0.1}$ in the fusion zone, from 314 to $464 \mathrm{HV}_{0.1}$ in HAZ near DP980 steel, and from 181 to $380 \mathrm{HV}_{0.1}$ in HAZ near LAD340 steel. The tensile strength of the fiber laser welded joints was $460 \mathrm{MPa}$ and it reached the strength of the LA340 steel base material with failure occurring in this steel.

Keywords: dual-phase steel, high-strength low-alloy steel, fiber laser welding, microstructure, microhardness, tensile strength.

Introduction. Dual-phase (DP) steels have attracted the attention of researchers because of some advantages stemming from their excellent properties. DP steels have superior mechanical properties compared to standard steels, moderate price due to a small amount of alloying additions, as well as good weldability and formability. They can be used in many applications as structural components. In the manufacturing of lightweight automobiles, they enable to reduce fuel consumption without compromising other attributes such as safety, performance, recyclability, and cost. The excellent mechanical properties of DP steels are the consequence of their multiphase structure which can consist of different portions of ferrite and martensite. Fine-grained ferritic martensitic structure of DP steels enables the high tensile strength up to $1200 \mathrm{MPa}$ with unit elongation up to $27 \%$ [1-7]. High-strength low-alloy (HSLA) steels are the important part of high-strength steels. Although they are still predominately used in structural applications, their application in auto industry is rapidly increasing. Due to the low carbon and alloying element content, HSLA steels have mainly ferritic microstructure. This microstructure is the consequence of lower strength, but better formability and weldability compared to DP steels [6-9].

Both DP and HSLA steels can be profitably used in tailor welded blanks (TWBs). The TWBs are semi-finished parts that consist of at least two single sheets that are welded together prior to the forming process. The sheets can exhibit different mechanical properties, thickness or coatings. Using TWBs enables an adaptation to locally different loading conditions or other requirements in the part. The most important advantage of a part made from TWBs consisting of high-strength steels is the weight reduction up to $25 \%$ compared to conventional products. Other advantages of using DP steels with HSLA steels in TWB parts is a good ration of strength deformation properties. The DP steels assignee the 
strength of the part and HSLA steels assignee the deformation zone because of their excellent formability [9-12].

The joining of TWBs is usually done by laser welding, but other weld techniques are also possible. Among commercial laser systems, fiber lasers have the characteristics of excellent beam quality and high brightness accompanied with low heat input. Low heat input is the consequence of small fusion zone (FZ) and heat-affected zone (HAZ) and the lower cost and greater flexibility compared to other welding methods. Low heat input produces the fine grain structures that provide the strength and toughness of the joints and has the benefit of decreasing welding thermal distortion [13-15].

The microstructure created after fiber laser welding is important for final properties of joints and applications of TWBs welded by a laser process. The microstructure changes accompanying the laser welding increase the strength in weld region of TWB but also worsens its formability. The proper microstructure assures proper ratio between strength and formability. The microstructure is affected mainly by the chemical composition of base materials, sheets thicknesses and welding parameters such as power input, welding speed, and others. Several works were devoted to the laser welding of different high-strength steel steels [15-20]. This work was concentrated on microstructure and microhardness characteristics of fiber laser welded joints of DP980 and LA340 steels.

Experimental Procedure. Both DP980 and LA340 steel sheets with a thickness of $1.2 \mathrm{~mm}$ and zinc coating of $100 \mathrm{~g} / \mathrm{m}^{2}$ were used for fiber laser welding. The chemical composition of the experimental steels is given in Table 1 and their mechanical properties are compared in Table 2. Used steels differ in contents of alloying elements. As the DP980 dual-phase steel has a higher amount of these elements, it is the consequence of a higher strength and lower plasticity compared to LA340 steel (Table 2).

$\mathrm{T}$ a b 1 e 1

Maximal Concentration (wt.\%) of Alloying Elements in Experimental Steels

\begin{tabular}{|c|c|c|c|c|c|c|c|c|c|c|c|c||}
\hline Steel & $\mathrm{C}$ & $\mathrm{Mn}$ & $\mathrm{Si}$ & $\mathrm{Al}$ & $\mathrm{P}$ & $\mathrm{S}$ & $\mathrm{V}$ & $\mathrm{B}$ & $\mathrm{Nb}$ & $\mathrm{Ti}$ & $\mathrm{Cr}$ & Mo \\
\hline DP980 & 0.23 & 2.7 & 0.8 & 0.015 & 0.08 & 0.015 & 0.2 & 0.005 & \multicolumn{2}{|c|}{1.0} & \multicolumn{2}{|c|}{0.2} \\
\hline LA340 & 0.11 & 1.0 & 0.5 & 0.015 & 0.03 & 0.025 & - & - & 0.09 & 0.15 & - & - \\
\hline
\end{tabular}

$\mathrm{T}$ a b 1 e 2

Mechanical Properties of Experimental Steels

\begin{tabular}{|c|c|c|c||}
\hline Steel & Tensile strength $(\mathrm{MPa})$ & Proof strength (MPa) & Elongation (\%) \\
\hline DP980 & $980-1130$ & $660-780$ & min. 10 \\
\hline LA340 & $410-510$ & $340-420$ & min. 21 \\
\hline
\end{tabular}

The welding experiments were done on the ytterbium type solid-state fiber laser IPG YLS-5000 with maximum output of $5000 \mathrm{~W}$, wave length of $1060 \mathrm{~nm}$ and fiber diameter of $100 \mu \mathrm{m}$ and with the welding head Precitec YW52 at the distance of $250 \mathrm{~mm}$ from the welded sheets. Welding experiments were conducted on sheets with a length of $200 \mathrm{~mm}$ and width of $100 \mathrm{~mm}$ along the longitudinal edge. The welded surfaces were milled and cleaned with acetone. The butt joints without filler metal and without shielding atmosphere were prepared at beam power from 750 to $5000 \mathrm{~W}$ and welding speed from 10 to 120 $\mathrm{mm} / \mathrm{s}$. These parameters influenced the microstructure and the properties of joints, but in this paper, the joints fibers laser-welded at beam power of $3200 \mathrm{~W}$ and a welding speed of $70 \mathrm{~mm} / \mathrm{s}$ were evaluated. 
The stereomicroscope Zeiss was used to observe the macrostructures of welded joints. The microstructure was studied on samples cut off the welded joints and prepared using standard metallographic techniques. The microstructures were observed using Axiovert 40MAT light microscope, JEOL JSM-IT300 scanning electron microscope. Energy-dispersive spectroscopy (EDS) was employed for chemical analysis of created phases. Image analysis was used to measure grain sizes. Microhardness profiles were measured on transverse sections of welded joints using a Vickers indenter with a load of $100 \mathrm{~g}$. The samples for tensile tests were prepared from welded joints and tests were carried out using universal testing machine Instron 195 at room temperature and crosshead speed of $10 \mathrm{~mm} / \mathrm{min}$.

\section{Results and Discussion.}

The Macrostructure of Fiber Laser-Welded Joint. The macrostructure of welded joint with its subzones prepared at the beam power of $3200 \mathrm{~W}$ and the welding speed of $70 \mathrm{~mm} / \mathrm{s}$ can be seen in Fig. 1. The FZ in the center of the joint has thickness approximately from 0.7 to $1.2 \mathrm{~mm}$. The DP980 steel BM is on the left and the LAD340 steel BM is on the right of Fig. 1. The HAZ near DP980 steel with a thickness from 0.5 to $0.7 \mathrm{~mm}$ is between the FZ and DP980 steel and the HAZ near LA340 steel with thickness from 0.3 to $0.4 \mathrm{~mm}$ is between the FZ and LAD340 steel. The subzones are characterized by quite narrow shapes which are typical for keyhole welding. The joint is characterized with the slight concavity of the face and root sagging, but other defects such as porosity, cracks weren't observed. The grain size within both HAZs decreased with the distance from the weld boundaries according to different peak temperatures reached during the welding thermal cycle. The coarse-grained regions were created near the FZ with the highest peak temperatures but still under the melting point.

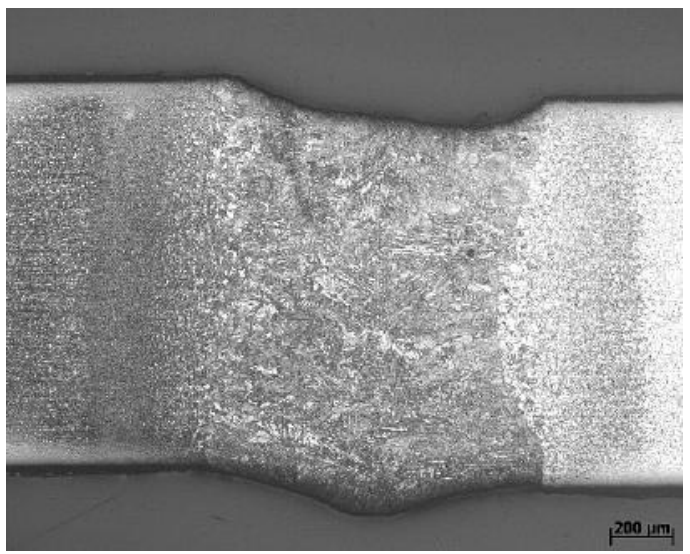

Fig. 1. Macrostructure of fiber laser welded joint of DP980 steel with LA340 steel.

Microstructures in Subzones of Fiber Laser Welded Joint. The micrograph of DP steel DP980 is in Fig. 2 and it is characterized by equiaxed very fine-grained morphology built of a ferritic matrix with grain size in the interval from 5 to $10 \mu \mathrm{m}$. In the ferritic matrix, equiaxed martensitic grains with size from 1 to $3 \mu \mathrm{m}$ precipitated in rows. The portion of martensite and ferrite is approximately equal.

The microstructure of HSLA steel LA340 in Fig. 3 has mainly equiaxed morphology. The matrix is built by ferrite with slight heterogeneity in the grain size in the interval from 2 to $15 \mu \mathrm{m}$. Small islands of perlite and tertiary cementite were observed an identified using EDS analysis at the ferritic grain boundaries.

The microstructure in FZ of the weld is documented in Fig. 4. The microstructure consists of coarse columnar dendritic grains, which are perpendicular to the fusion boundary in the direction of the maximal rate of heat removing. The microstructure of FZ 


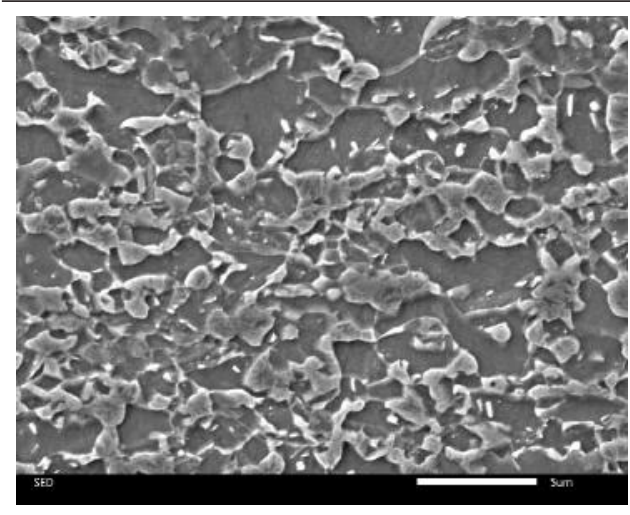

Fig. 2. Microstructure of DP980 steel.



Fig. 3. Microstructure of LA340 steel.



Fig. 4. Microstructure in FZ of the weld.

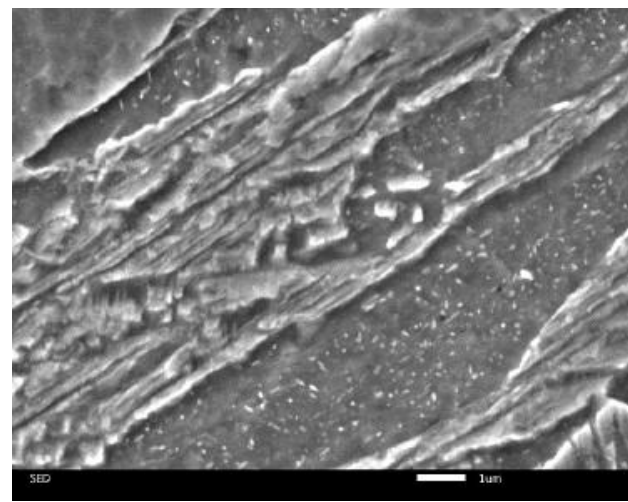

Fig. 5. Lower bainite in FZ of the weld.

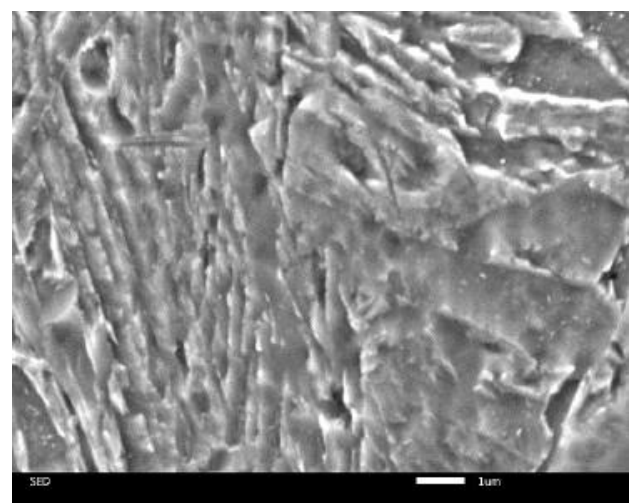

Fig. 6. Martensite in FZ of the weld.

had acicular morphology. It consists mainly of lower bainite and martensite. The characteristics of these microstructures observed at higher magnification are in Figs. 5 and 6.

The detail of lower bainite in FZ can be seen in Fig. 5. Fine carbides, identified as MC and $\mathrm{M} 3 \mathrm{C}$ carbides, are precipitated inside the bainitic laths and can be seen in Fig. 5. Presence of these phases and their morphology confirms the identification of lower bainite.

Large areas of martensite in the substructure of FZ can be seen in Fig. 6. Morphological characteristic of low carbon martensite with lath packets can be seen in Fig. 6 . 
The microstructures within both HAZs from Figs. 7-10 were created under the effect of thermal weld cycle. As the chemical compositions of both steels are different, the different microstructures in both HAZs were observed. Since the DP980 steel contains a larger concentration of alloying elements as compared to LAD340 steel, the HAZ microstructure near DP980 steel consisted mainly of lath macroconstituents build in packets. The microstructures of both HAZs got finer with the distance from the fusion boundary. The microstructure in the coarse-grained region of HAZ near DP980 steel in the vicinity of fusion boundary is documented in Fig. 7. The coarsening of former austenitic grains was observed in the region of HAZ near DP980 steel heated above $\mathrm{A}_{3}$ transformation temperature and with average prior austenite grain size of $20 \mu \mathrm{m}$. HAZ consists mainly of martensite, but also of lower bainite and occasionally of MC carbides precipitates.

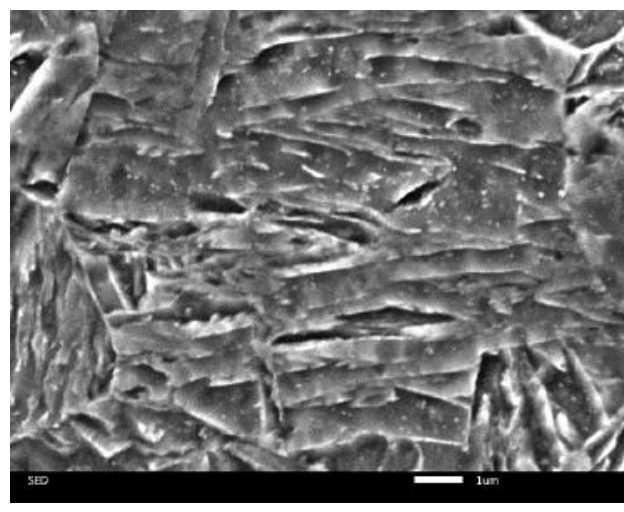

Fig. 7. Coarse-grained region of HAZ near DP980 steel.

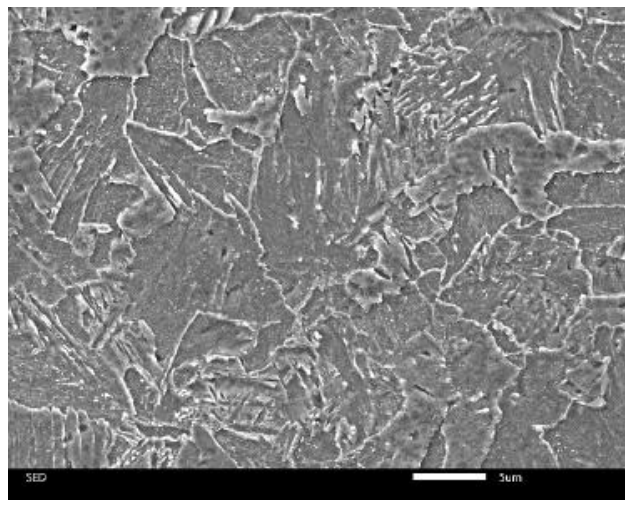

Fig. 9. Coarse-grained region of HAZ near LA340 steel.

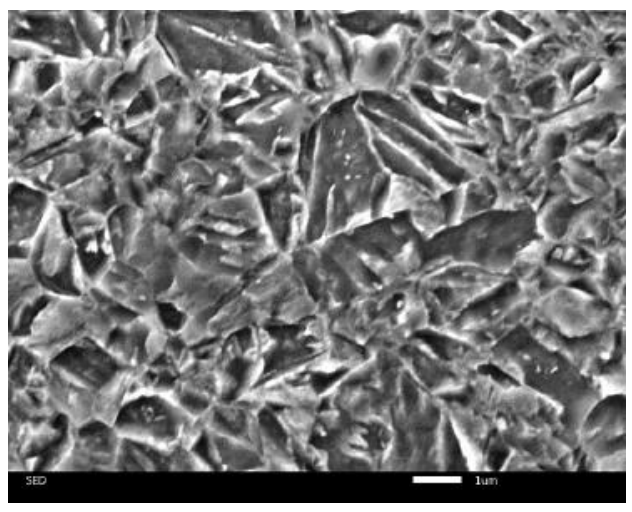

Fig. 8. Fine-grained region of HAZ near DP980 steel.

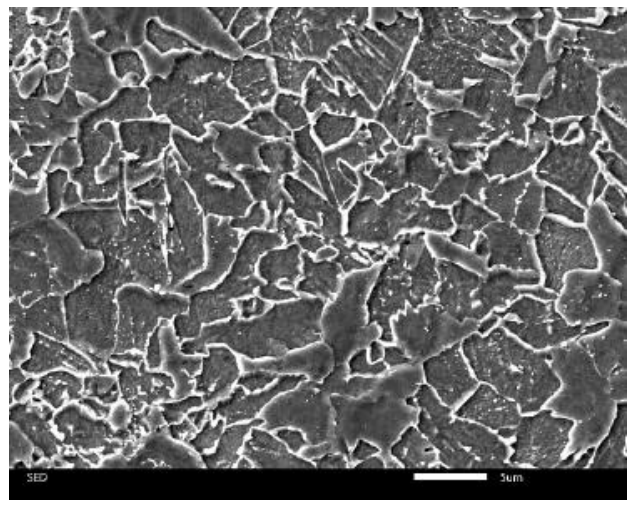

Fig. 10. Fine-grained region of HAZ near LA340 steel.

In the region of HAZ near DP steel DP980 (Fig. 8) heated in inter-critical temperature interval fine-grained region created and microstructure consisted of equiaxed ferrite and tempered martensite.

The microstructure of the HAZ near LA340 steel can be seen in micrograph Fig. 9 and 10. In the high tempered region of HAZ near HSLA steel LAD340 heated above $\mathrm{A}_{3}$ temperature but under the melting point of steel (Fig. 9), the coarsening of former austenitic grains was observed with the average grain size of $40 \mu \mathrm{m}$. The microstructure is built of ferrite, acicular ferrite, upper bainite, pearlite which precipitated at former austenitic grains.

In the low-tempered region of HAZ near LA340 steel fine-grained only equiaxed ferritic microstructure with average grain size of $3 \mu \mathrm{m}$ was found (Fig. 10). 
Microhardness Profile across the Welded Joint. The microhardness profile measured across the midsection of the welded joint is presented in Fig. 11. The microhardness profile is characterized by increased microhardness values in both HAZs from BMs towards the FZ. HAZ softening is visible in the vicinity of DP980 steel BM. The hardness of DP980 steel BM was in the interval from 320 to $350 \mathrm{HV}_{0.1}$ and with an average value of $335 \mathrm{HV}_{0.1}$ and this value represents a ferritic-martensitic microstructure of DP980 steel with the equal portion of both phases. However, the microhardness in interval from 181 to $190 \mathrm{HV}_{0.1}$ and with an average value of $186 \mathrm{HV}_{0.1}$ measured for LA340 steel represents mainly ferritic structure of the LA340 steel. The microhardness values in FZ were in the interval from 380 to $440 \mathrm{HV}_{0.1}$ and correspond well the microstructure built of lower bainite and martensite. The microhardness in HAZ near LA340 was in the interval from 181 to $380 \mathrm{HV}_{0.1}$ and the microhardness in HAZ near DP980 steel was from 314 to $464 \mathrm{HV}_{0.1}$. The value of $464 \mathrm{HV}_{0.1}$ was the highest measured microhardness and it was measured in the coarsegrained region of HAZ near DP980 steel with the dominant presence of coarse martensite. The smallest value in this HAZ was $314 \mathrm{HV}_{0.1}$ and was measured in the vicinity of DP980 steel $\mathrm{BM}$ and represents the softening region with mainly fine ferritic microstructure.

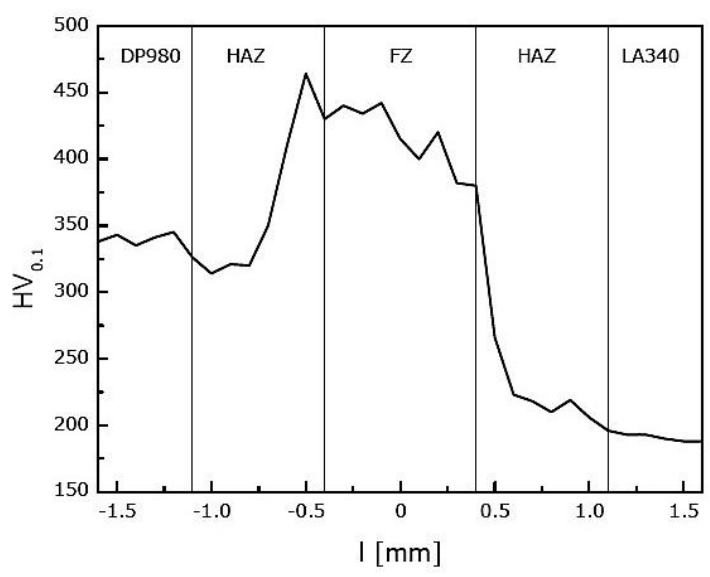

Fig. 11. Microhardness profile across the welded joint.

The microhardness values in certain subzones of fiber laser welded joints could be confronted with values measured at fiber laser welding of two types of joints DP600 with BH220 (bake-hardening steel) and DP980 with BH220 published in previous papers [21-23]. In the papers [21, 22] welded joints of DP600 steel grade with BH220 steel grades with a thickness of $1.2 \mathrm{~mm}$ were evaluated. The average microhardness of DP600 steel was $220 \mathrm{HV}_{0.1}$ and it represents the ferritic martensitic microstructure with the dominant portion of ferrite. As the DP980 grade steel has a higher concentration of carbon and alloying elements, it is the consequence of an approximately equivalent portion of martensite and ferrite and the average hardness of $335 \mathrm{HV}_{0.1}$. The difference is also between LA340 grade steel and BH220 grade steel. As the LA340 steel has a higher content of carbon and alloying element compared to BH220 steel, the microstructure of LA340 steel consists without ferritic matrix of small portion of pearlite and tertiary cementite instead of the whole ferritic microstructure of BH220 steel. The microhardness of LA340 steel is $186 \mathrm{HV}_{0.1}$ and below $150 \mathrm{HV}_{0.1}$ for BH220 steel. These differences in base metals compositions influenced the microhardness in FZ and both HAZs and they were lower in case of joints DP600 with BH220 steel in comparison to joints of DP980 with LA340. The microhardness in FZ of DP600 with BH220 joints was in the interval from 265 to $375 \mathrm{HV}_{0.1}$ (depending on the process parameters), but from 380 to $440 \mathrm{HV}_{0.1}$ in case of DP980 with LA340 joints. The 
microhardness values corresponded with microstructure. The dominant microstructure in FZ of DP980 with LA340 steel was lower bainite and martensite, in FZ of DP600 with LA220 steel it was acicular ferrite, bainite, and martensite. HAZ near DP600 steel reached microhardness values from 195 to $435 \mathrm{HV}_{0.1}$ compared to HAZ near DP980 steel with microhardness values from 314 to $464 \mathrm{HV}_{0.1}$. The microstructure in HAZ near DP980 steel was built by martensite and lower bainite, but the microstructure in HAZ near DP600 steel consisted of martensite and lower bainite too. The highest microhardness values were reached in HAZ near DP steel for both types of joints and with higher values for DP980 steel. The microhardness in HAZ near BH220 steel was in the interval from 135 to $298 \mathrm{HV}_{0.1}$ compared to HAZ near 340LA steel with values from 181 to $380 \mathrm{HV}_{0.1}$. The microstructure in HAZ near LA340 steel was built of ferrite, acicular ferrite, and upper bainite, but the microstructure in HAZ near BH220 steel consisted of ferrite and acicular ferrite. The softening region in HAZ near DP600 steel reached the minimal hardness of $195 \mathrm{HV}_{0.1}$ (decreasing from average hardness of base metal $220 \mathrm{HV}_{0.1}$ ) compared the softening region in HAZ near DP980 steel which reached the minimal hardness of $314 \mathrm{HV}_{0.1}$ (decreasing from average hardness of base metal $335 \mathrm{HV}_{0.1}$ ). Both softening regions were built by equiaxed ferrite with fine grains $[21,22]$. The microhardness values measured for a welded joint of DP980 with BH220 steel and with a thickness of $1.2 \mathrm{~mm}$, studied in [23], were between values measured at previous types of joints because of a medium concentration of alloying elements. The microhardness in FZ of DP980 with BH220 joints was in the interval from 300 to $450 \mathrm{HV}_{0.1}$ depending on process parameters. HAZ near DP980 steel reached microhardness values from 363 to $465 \mathrm{HV}_{0.1}$ and the microhardness in HAZ near BH220 steel was in the interval from 181 to $369 \mathrm{HV}_{0.1}$ for welded joint of DP980 with BH220 steel [23].

Tensile Tests of the Welded Joints. The tensile tests showed the average weld strength of $460 \mathrm{MPa}$ and the average elongation of $9.3 \%$. The weld strength was higher than the tensile strength of less strong LAD340 steel because all tensile tested samples broke in LA340 steel base material as can be seen in Fig. 12. The results of tensile tests were in line with the microhardness results. The elongation was less than the average value of both DP980 and LA340 steel, which was the consequence of strengthening of weld subzones by the laser fiber welding (Fig. 11).

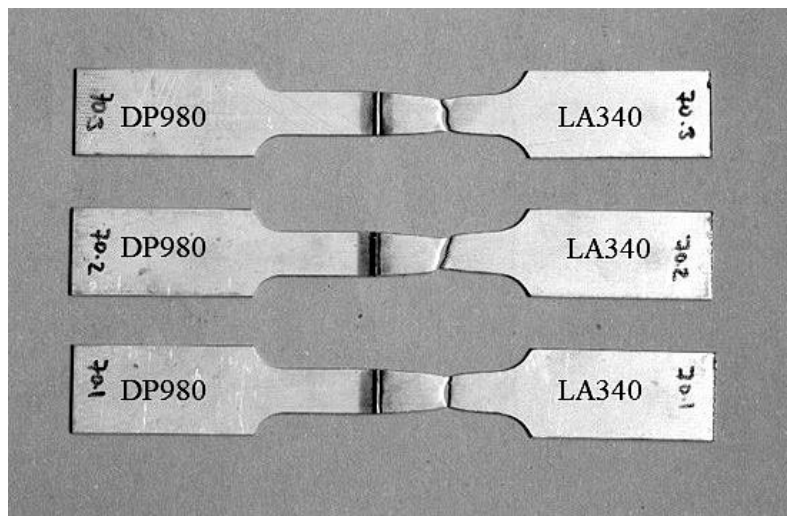

Fig. 12. Tensile samples of welded joints after the tests.

Conclusions. The fiber laser welding of dual-phase DP980 steels with high-strength low-alloyed LA340 steels was studied. The butt welds prepared with a fiber laser process were characterized with a slight concavity of the face and root sagging, but without the negative effect of these imperfections on the tensile strength of the joints because all welded specimens failed in the LA340 steel during the tensile tests. 
The dominant presence of lower bainite and martensite was found in the FZ of the welded joint. Laths of these macroconstituents were built in packets within a large columnar grain structure and were the consequence of rapid cooling. The microstructure in the coarse-grained region of HAZ near DP980 steel near fusion boundary was built mainly of martensite, lower bainite and occasionally by MC carbides precipitates. The microstructure consisted of equiaxed ferrite and tempered martensite in the fine-grained region of HAZ near DP steel DP980 heated in temperature interval between $A_{1}$ and $A_{3}$. In the hightempered coarse-grained region of HAZ near LA340 steel ferrite, acicular ferrite, upper bainite, and pearlite, which precipitated in former austenitic grains were observed. In the low-tempered region of HAZ near HSLA steel LA340, only the fine-grained equiaxed ferritic microstructure was found.

Microhardness profile across the welded joint was characterized with increased microhardness values in FZ and both HAZs. The maximum microhardness across the welded joint was measured within the HAZ near DP980 steel with the value of $464 \mathrm{HV}_{0.1}$. The maximal hardness in the HAZ near LA340 steel reached $380 \mathrm{HV}_{0.1}$. The hardness in the FZ was in the interval from 380 to $440 \mathrm{HV}_{0.1}$. The smallest value of microhardness $314 \mathrm{HV}_{0.1}$ measured in HAZ near DP980 steel represented the HAZ softening in this subzone of the welded joint. Measured microhardness values were in good agreement with microstructure identification. The tensile strength of the fiber laser welded joints was $460 \mathrm{MPa}$ and it reached the strength of the LA340 steel base material with failure occurring in this steel.

Acknowledgments. This work was supported by the Slovak Research and Development Agency under the contract No. APVV-0281-12.

1. Q. L. Cui, D. Parkes, D. Westerbaan, et al., "Effect of coating on fiber laser welded joint of DP980 steels," Mater. Design, 90, 516-523 (2016).

2. D. Yan, C. C. Tasan, and D. Raabe, "High resolution in situ mapping of microstrain and microstructure evolution reveals damage resistance criteria in dual phase steels," Acta Mater., 96, 399-409 (2015).

3. W. Xu, D. Westerbaan, S. S. Nayak, et al., "Tensile and fatigue properties of fiber laser welded high strength low alloy and DP980 dual-phase steels joints," Mater. Design, 43, 373-383 (2013).

4. J. Wang, L. Yang, M. Sun, et al., "Effect of energy input on the microstructure and properties of but joints in DP1000 steel laser welding," Mater. Design, 90, 642-649 (2016).

5. M. Rossini, P. Russo Spena, L. Cortese, et al., "Investigation on dissimilar laser welding of advanced high strength steel sheets for the automotive industry," Mater. Sci. Eng. A, 628, 288-296 (2015).

6. N. Farabi, D. L. Chen, and Y. Zhou, "Microstructure and mechanical properties of laser welded dissimilar DP600/DP980 dual-phase steel joints," J. Alloy. Compd., 509, 982-989 (2011).

7. Y. Mazaheri, A. Kermanpur, and A. Najafizadeh, "Nanoindentation study of ferritemartensite dual phase steels developed by a new thermomechanical processing," Mater. Sci. Eng. A, 639, 8-14 (2015).

8. D. Parkes, D. Westerbaan, S. S. Nayak, et al., "Tensile properties of fiber laser welded joints of high strength low alloy and dual-phase steels at warm and low temperatures," Mater. Design, 56, 193-199 (2014).

9. D. Parkes, W. Xu, D. Westerbaan, et al., "Microstructure and fatigue properties of fiber laser welded dissimilar joints between high strength low alloy and dual-phase steels," Mater. Design, 51, 665-675 (2013). 
10. J. Vinas and M. Abel, "Analysis of laser welds on automotive steel sheets," Mater. Sci. Forum, 818, 239-242 (2015).

11. D. C. Saha, D. Westerbaan, S. S. Nayak, et al., "Microstructure-properties correlation in fiber laser welding of dual-phase and HSLA steels," Mater. Sci. Eng. A, 607, 445-453 (2014).

12. A. K. Sinha, D. Y. Kim, and D. Ceglarek, "Correlation analysis of the variation of weld seam and tensile strength in laser welding of galvanized steel," Opt. Laser Eng., 51, 1143-1152 (2013).

13. J. Meško, A. Zrak, K. Mulczyk, and S. Tofil, "Microstructure analysis of welded joints after laser welding," Manuf. Technol., 14, 355-359 (2014).

14. J. Ma, F. Kong, W. Liu, et al., "Study on the strength and failure modes of laser welded galvanized DP980 steel lap,” J. Mater. Process. Tech., 214, 1696-709 (2014).

15. H. Hazratinezhad, N. B. Mostafa Arab, A. R. Sufizadeh, and M. J. Torkomany, "Mechanical and metallurgical properties of pulsed neodymium-doped yttrium aluminum garnet laser welding of dual phase steels," Mater. Design, 33, 83-87 (2012).

16. J. H. Lee, S. H. Park, H. S. Kwon, et al., "Laser, tungsten inert gas, and metal active gas welding of DP780 steel: Comparison of hardness, tensile properties and fatigue resistance," Mater. Design, 64, 559-565 (2014).

17. D. Dong, Y. Liu, Y. Yang, et al., "Microstructure and dynamic tensile behavior of DP600 dual phase steel joint by laser welding," Mater. Sci. Eng. A, 594, 17-25 (2014).

18. Y. X. Chen, C. D. Yang, X. J. Wang, and H. B. Chen, "Evaluation of metal-active gas double-sided double-power arc welded joints of high-strength low-alloy steel," Strength Mater., 47, No. 1, 164-169 (2015).

19. K. M. Hong and Y. C. Shin, "Prospects of laser welding technology in the automotive industry: A review," J. Mater. Process. Tech., 245, 46-69 (2017).

20. W. Xu, D. Westerbaan, S. S. Nayak, et al., "Microstructure and fatigue performance of single and multiple linear laser welded DP980 dual-phase steel," Mater. Sci. Eng. A, 533, 51-58 (2012).

21. P. Švec, A. Schrek, and T. Csicsó, "Fiber laser welding of dual-phase and bakehardened steels," Strength Mater., 48, No. 4, 481-486 (2016).

22. P. Švec, A. Schrek, and M. Dománková, "Microstructure of fibre laser welded joint of dual phase steel with bake hardening steel," Metallic Mater., 54, No. 6, 407-416 (2016).

23. P. Švec and A. Schrek, "Microstructure of fibre laser welded butt joints," $M M$ (Modern Machinery) Science Journal, November, 1304-1308 (2016). 